\title{
Generic Features of Evolution and Its Continuity: A Transdisciplinary Perspective
}

\author{
Ulrich WITT
}

\begin{abstract}
Because of the intellectual attraction of the neo-Darwinian theory of evolution, its concepts are often borrowed to conceptualized evolutionary change also in non-biological domains. However, a heuristic strategy like that is problematic. An attempt is therefore made to identify generic features of evolution which transcend domain-specific characteristics. Epistemological, conceptual, and methodological implications are discussed, and the ontological question is raised how non-biological evolutionary theories can be accommodated within the Darwinian world view of modern sciences.
\end{abstract}

Keywords: Darwinism, emergence, evolution, evolutionary ontology, novelty.

\section{Introduction}

The integration of Darwin's theory, and later the neo-Darwinian synthesis, into the modern scientific world view was probably the most challenging intellectual endeavor of the last century. It reflects the overwhelming success of the "Darwinian revolution" (Ruse 1979) in the sciences. However, some questions remain. One that will be discussed here relates to the role which a Darwinian world view offers for understanding evolution as a general phenomenon. Evolution is not specific to the realm of nature. Phenomena of evolution also occur in other domains. The social sciences are a case in point. What is the relevance of Darwinism, e.g., for understanding societal evolution? Early attempts at applying Darwinian thought to the human society resulted in Social Darwinism (Hawkins 1997). This proved to be a misinterpretation with disastrous consequences. For long time this experience made many social scientists reluctant to even consider the possibility of a connection between Darwinian thought and the social sciences.

These discouraging experiences not withstanding, the issue deserves attention, given the enormous impact of Darwinism on modern scientific thought. It can be dealt with in a more abstract way (which, as far as the social sciences are concerned, is less prone to the fallacies of Social Darwinism) by asking whether Darwinian concepts are sufficiently general to explain evolutionary processes wherever they are thought to occur. There is a strong tendency nowadays to explicitly or implicitly answer this question in the affirmative. Many writers openly or tacitly borrow from evolutionary biology. It has become something of "the" model for evolutionary theorizing in many disciplines, and the neo-Darwinian approach to evolution in nature has in the meantime mutated to "Universal Darwinism" (Dawkins 1983).

However, as will be argued in this paper, for understanding phenomena of evolution outside the domain of biology, such an approach is neither necessary nor does it seem well suited. The idea that Universal Darwinism has identified the generic features of evolution can be contested. To make that point, the case of the social sciences, and more specifically, of economics will be discussed exemplarily. Since neoDarwinian theory could be considered relevant at several levels in the economic do- 
main, a rather complex argument will be necessary, one which results in the hypothesis of an ontological continuity of evolution. Section II prepares the ground by briefly reviewing some attempts to come to grips with the role which evolution plays in economics. In this light, Section III discusses the concepts for explaining evolution suggested by Universal Darwinism and develops an alternative approach to identifying the generic features of evolution. Section IV elaborates on the epistemological implications of those generic features and some of their methodological consequences. Section $\mathrm{V}$ then returns to the question of what relevance can be attributed to Darwinian thought in the trans-disciplinary approach taken here. Section VI offers some conclusions.

\section{Responses in Economics to the Challenge of Darwinism}

The influence of contemporary Darwinian thought on the first efforts to conceive an evolutionary approach to economics more than a century ago is quite obvious. Thorstein Veblen, then a widely read author, published an article with the provocative title "Why is Economics not an Evolutionary Science?" (Veblen 1898). His article was more of a criticism of the static economic theory of his time than an outline of an alternative evolutionary program. Nevertheless, in later work, Veblen $(1899,1914)$ tried to reconstruct and interpret the anthropological record of how institutions and technologies had developed from a primitive state of human society. As he had already posited in his programmatic article, to him the historical change in man-made evolution was cumulative and followed the path of the evolution of the habits of thought. Unfortunately, despite his impressive elaboration of the historical process inspired by the scientific ideals of the German historical school (cf. Hodgson 2001), Veblen failed to provide a systematic theoretical account of economic evolution and its relationship to Darwinian theory ${ }^{1}$.

While Veblen's approach to evolutionary economics was clearly inspired by a Darwinian world view, the other early attempt to address the issue was explicitly antiDarwinian. It was undertaken by Joseph Schumpeter in his influential theory of economic development (Schumpeter 1912/34). He denied Darwinism any relevance for understanding economic evolution, in fact, he even avoided using the term "evolution" in this context. The inspiration for his approach seems to have come from another major intellectual controversy of the time, namely the debate on Marx's theory of a crisis-prone capitalist development of the economy (which may be subsumed to the class of pre-Darwinian evolutionary thought). The growth process in the period of "promoterism" in Europe in the late $19^{\text {th }}$ and early $20^{\text {th }}$ century had created previously unknown forms of economic reality in production, consumption, exchange, and even in the institutional set up of the economy. In Schumpeter's view, theorizing about capitalist development would be pointless, if it failed to take account of innovations and the role of entrepreneurship. Since he rejected biological analogies, Schumpeter had to

${ }^{1}$ Cf. Rutherford (1998). The theoretical deficit left the school which Veblen founded (American Institutionalism) somewhat disoriented and was never compensated in that school -- perhaps one of the reasons for why this first attempt to establish "evolutionary economics" was later lost from sight (Hodgson 1999, Chap. 5). 
find a way to make sense of economic evolution without recourse to Darwinian concepts. He tried to achieve this by focusing on entrepreneurial innovations and their diffusion.

However, Schumpeter fell short of realizing the potential of his ingenious insight which could have led him to recognize the emergence and dissemination of novelty as generic features of evolution. With a somewhat artificial distinction between invention and innovation, and the assumption that inventions are always already given, he stopped half way in his investigation of endogenously generated economic change. By refusing to consider inventions -- or, more generally, novelty -- more closely, an explanation of how knowledge is created, and why, is made exogenous to Schumpeter's theory. By the same token, the question of whether a feed-back between search, discovery, experimentation, and adoption of new possibilities (and the respective motivations) exists is excluded. Moreover, perhaps as a tribute to the debate on Marxism, Schumpeter chose to cast what he called his "developmental method" in terms of a theory of unsteady capitalist development, i.e. of business cycle theory. When he discussed how entrepreneurs carry out innovations and, by doing so induce development "from within the economy", the upshot of his discussion was that these innovative activities occur in regular cyclical patterns of economic growth.

For reasons discussed elsewhere (Witt 2002), Schumpeter was unable to establish what could have been a Schumpeterian evolutionary school. It was only in a more recent manifesto by Nelson and Winter (1982) -- which triggered a new wave of evolutionary economics (Nelson 1995) -- that his ideas about capitalist development have been revived. Remarkably enough, in this revival, his ideas are blended with Darwinian conceptions -- despite Schumpeter's own rejection of any analogies to Darwinian thought. This is an obvious tribute to the above mentioned increasing impact which (neo-) Darwinian evolutionary biology has had as "the" model of an evolutionary science. This impact is also visible in the recent surge of interest of economists in evolutionary game theory which originated from evolutionary biology².

It may therefore be asked at this point how pertinent Darwinian thought is for coming to grips with evolution in the economic domain. The answer to this question is complicated by the fact that there are many possible ways of referring to Darwinian thought. One point in which the diverse ways differ is their ontological foundation. In fact, there seem to be only two alternative ontological positions. Either evolutionary economics is assumed to share its ontological basis with neo-Darwinian evolutionary biology or the idea of a common ontological basis is (often implicitly) rejected. Prominent examples of the latter position are the various attempts to construction analogies to, and the metaphorical uses of, Darwinian concepts to be discussed now in mo-

\footnotetext{
2 Cf. Maynard Smith (1982). Symptomatic of the current situation in economics, the development in evolutionary game theory is entirely disconnected from the revival of Schumpeterian evolutionary economics. No attempt is made to identify a common ontological basis as is clearly brought out in a recent symposium on evolutionary economics (Bergstrom 2002, Nelson and Winter 2002, Robson 2002, Samuelson 2002). In fact, few attempts are made at all in evolutionary game theory to explicate the relevance of this theory for economics. For notable exceptions cf. Binmore (1998) and Young (1998).
} 
re detail. Examples of differing versions of the former position will be considered in later sections.

A popular strategy for pursuing Darwinian ideas for heuristic purposes is the construction of analogies. Without pretending to imply any commonality at the ontological level, analogies are drawn between principles of evolution in the biological domain on the one hand and the economic domain on the other. However, because of obvious differences between the two domains, analogies rarely really hold. Other than by way of a (probably unnoticed) mistaken analogy, the actual use made of Darwinian concepts in evolutionary economics is therefore often only a metaphorical one. This means borrowing Darwinian concepts to conceive and express conjectures about evolution in the economic domain. Particularly popular is the recourse to the selection metaphor (see below). The value of these heuristic strategies is difficult to assess in general. The potentially fruitful heuristic of a metaphor has to be weighed against the potential perils of being attracted to, and trapped in, mistaken analogies which may then for long time be difficult to correct. The way in which Darwinian concepts have been made part of neo-Schumpeterian evolutionary economics illustrates the pros and cons.

In the 1950s a first debate about "economic natural selection" started in the context of rivaling hypotheses about the pricing setting behavior of firms (Alchian 1950, Penrose 1952). These hypotheses either postulated profit maximizing behavior or some form of non-maximization. Observational problems prevented a conclusive discrimination between the rivaling hypotheses being made on an empirical basis. The question was therefore raised as to whether a logical argument for discriminating between the alternative hypotheses could be derived from an analogy to natural selection. The basic rationale that was proposed assumed that, under conditions of competitive markets, all forms of non-maximizing firm behavior would fall victim to selection forces. However, the profit level that actually suffices to survive in a particular market at a particular time hinges on the behavior of the competitors -- a dependency called "occupancy effect" in the biological analogue. No analogue to a genetic continuity being present in the highly volatile pricing behavior of firms, the occupancy effect in this context hinges on a large number of situational factors so that, as a survival criterion, profitability says very little (cf. Winter 1964, Metcalfe 2003). In this context, "economic natural selection" is therefore a rather superficial metaphor of uncertain heuristic value.

Nonetheless, it has also been used in the "loose analogy" (as they call it) in Nelson and Winter's (1982) revival of Schumpeterian evolutionary economics. Informed by the notion of bounded rationality, they argue (ibid., Chap. 5) that in their internal interactions organizations are based on behavioral routines, rules of thumb, and regular interaction patterns. Production planning, calculation, price setting, and even the allocation of research and development funds, are all seen as following routine and rulebound behavior. Borrowing the Darwinian notions, the firms' routines are then interpreted as "genotypes" and the specific decisions resulting from the applied routines as "phenotypes". The latter are supposed to affect the firms' overall performance. 
Different routines and different decisions are assumed to imply differences in the firms' growth. On the assumption that routines which successfully contribute to growth are not changed, the actual expansion is interpreted as an increase in relative frequency of those "genes-routines", while routines which cause a deteriorating performance are unlikely to expand. Their relative frequency is therefore supposed to decline. Analogously to the principles of natural selection, the changing composition of behavioral routines within an industry is thus considered to be a significant instance of economic evolution. Yet, there is little to support the assumption that there are sufficient inertia in this development for the selection mechanism to effect systematic changes. The reason is that it is most likely that firms facing deteriorations will be induced to identify the deficient routines and to replace or improve them in a kind of intentionally produced mutation of their "genes" 3 .

Indeed, a more general limitation of the analogy between natural selection and "economic natural selection" turns up here. In the genetic context, selective forces operate on a given population and change the relative frequencies of the genes in the pool. The individual members of the population have little, if any, room for escaping from these pressures or for adjusting to them. In this sense, selection forces may be labeled "external". In a similar way, the anonymous competitive forces of the markets can be seen as external to the individual. The market participants unintentionally impose constraints on each other in their multilateral interactions, and these constraints may even force some of them out of business. Thus the population of agents on the supply and/or demand sides of a market may systematically change over time. But, unlike in the genetic case, the agents are not helpless when exposed to these changes. In fact, the systematic changes observable in markets may be attributed to a large extent to the individuals' attempts to anticipate the effects of the market forces and to take account of them. If successful, the effects of "external" selection are replaced by what would have to be labeled "internal" selection.

The deliberate, discretionary character of behavior adaptation in the economy has no equivalent in the domain of genetically coded behavior considered in evolutionary biology. The notion of natural selection therefore runs the risk of inducing a misleading heuristic which fails to (sufficiently) acknowledge a genuine feature of economic evolution -- the role played by learning and cognition. ${ }^{4}$ Cognitive processes like hy-

3 Nelson and Winter (ibid.) argue that such improvement or replacement activities are themselves subject to higher routines, and that the differential growth argument therefore applies once again. It may indeed be that firms activate higher problem solving routines on a regular basis when a crisis occurs or is expected to occur. Yet, the outcome of these problem solving routines is often more likely to depend on whose problem solving capacity is involved in those routines than on the routines themselves. In this case, the differential success of the problem solving process triggered cannot be derived from differences in those routines. Differential success is basically unpredictable (much like mutation in the genetic sphere). When different people are involved in the same routines at different times, development may be different. The inertia in what has been suggested as the analogue of the selection mechanism is lost.

4 The individuals' capacity to anticipate consequences of their behavior and to take account of them deliberately by searching for better solutions may be interpreted as a case of Lamarckian rather than Darwinian evolution (Nelson and Winter 1982, p.11). Allowing for a direct feedback from the phenotypic performance to genotypic traits is said 
pothesis formation and learning from insight are likely to produce adaptations which follow their own regularities. Emerging from a limited human information processing capacity -- which means that people are constrained in what they sense, learn, and perceive -- the regularities reflect mental processes which in both their dynamics and their outcome are not necessarily the same as the process of genetic selection.

\section{Generic Features of Evolution}

The social sciences have an independent, pre-Darwinian tradition of evolutionary thought (cf. Hayek 1967a; for its influence on Darwin, cf. Richards 1992). Social philosophers and lawyers of the eighteenth and nineteenth century reflected on what would nowadays be called "cultural evolution". Some of this thought had strong normative connotations, equating societal evolution with progress in some sense. ${ }^{5}$ However, this entire tradition is largely forgotten today. The intellectual impact of Darwin's thought has been so strong that the notion of evolution is now almost exclusively associated with the meaning given to it in evolutionary biology. As discussed in the previous section, attempts at conceptualizing evolution in the domain of the social sciences make use of doubtful analogies and metaphors borrowed from evolutionary biology rather than reflecting on proper domain-specific concepts of their own. This intellectual habit coincides (and is occasionally mixed up with) an attitude cultivated in the post-Darwinian natural philosophy of claiming general empirical relevance for the Darwinian conception of evolution under the heading of "Universal Darwinism" (Dawkins 1983).

As the label indicates, Universal Darwinism suggests applying Darwinian notions as general tools for explaining evolutionary phenomena wherever such phenomena are thought to be present. In practice this may not appear much different from the borrowing of concepts discussed in the previous section. Yet, the ontological presumption is a different one. It is claimed that the general applicability of certain Darwinian concepts rests on the fact that they represent the generic features of evolution. What are the concepts considered generally valid by Universal Darwinism? A frequently cited list has been given by Campbell (1965). He suggested the interactive concepts of variation, selection, and retention or replication of competing variants from a population of variants. Similarly, Dawkins (1986) speaks of "replicators" like genes or "memes" as units of selection whose variation and selective multiplication are behind all forms of evolution on this planet.

There is no doubt that these concepts -- gained by abstraction from the neoDarwinian synthesis in evolutionary biology -- characterize very general features of

to imply a "Lamarckian" -- rather than Darwinian -- theory of evolution (Knudsen 2001). Note, however, that hardly any Lamarckian population dynamics have ever been worked out and studied in the sciences and that, unlike those of an analogy to the advanced Darwinian dynamics, the implications (and the benefits) of an analogy to Lamarckian interpretations are therefore unclear.

${ }^{5}$ A special variant are theories of evolution in which society goes through a sequence of progressive stages as, e.g., in Marxian historical materialism. The problems of these theories are well known from the criticism articulated in Popper (1960). 
evolution in nature. ${ }^{6}$ But, as abstract reductions of the Darwinian principles, they are still domain-specific. Per se there is little reason to believe that principles derived by an isolated abstraction from evolution in one domain do indeed carry over to evolution in other domains. The proposition that the population based principles of variation, selection, and replication are generic to all forms of evolution -- evolution in nature as much as cultural evolution, say -- is not self-evident. Conclusive empirical support for the alleged general relevance of the abstract Darwinian principles has not yet been provided. It may therefore be argued that their application to the non-biological domain (such as the economic domain) is actually only yet another attempt to construct analogies -- just more abstract ones. Indeed, several of the concrete objections to the attempted analogies raised in the previous section may be repeated similarly here.

To give an example, consider the relationship between selection and variation. In evolutionary biology the absence of a systematic feedback between selection and variation is a test criterion for Darwin's theory. In the economic domain this is different. The comparatively recent achievements of intelligence and codified knowledge often allow people to invent their way out when threatened by selection forces. Such a feedback would have to be given the status of a systematic feature of adaptation, if adaption were to be cast in terms of an interplay between selection and variation. The consequences of this difference with respect to the character and the pace of the adaptive process are dramatic. The meaning of both selection and variation would actually have to change significantly when going from one domain to the other. Similar objections could be raised against the Darwinian assumption of "blindness" or randomness of the variation process which does not do justice to human intuition and creativity. Hence, even at a very abstract level, it is hard to see how analogies suggested by Universal Darwinism can hold.

This is not to say, however, that the idea of identifying generic features of evolution -- which is a good part of the motivation underlying Universal Darwinism -- is mistaken. This idea is based on the ontological assumption of some commonalities shared by all forms of evolution. What has just been criticized is neither the basic idea nor its underlying ontological presumption, but the particular way of trying to realize the idea: the abstract reduction of Darwinian principles does not lead to generic features of evolution. To identify the latter, an attempt needs to be made to transcend all domain-specific characteristics by abstracting from specific forms of evolution in several domains. The question thus is, by what features can evolution be characterized if its particularities in, say, nature, in human culture in general, or in the human economy in particular, are recognized.

The social philosopher John Morley (1874) argued long ago that "evolution is not a force but a process, not a cause but a law". Of course there are forces driving the process of evolution and causes playing a role in it. But Morley is right in claiming that these are not constituent features of evolution. Constituents rather are the dynamically unfolding character and the lawfulness, i.e. regularity, of the changes brought about by

\footnotetext{
6 They abstract, among other things, from the principles of descent and speciation which figure prominently in Darwin's original understanding, cf. Mayr (1991, Chap.4).
} 
evolution wherever it occurs. However, Morley's two properties are not sufficient. There are many processes which display regularities that are not evolutionary, e.g. the stochastic process describing the motion of a particle suspended in a liquid, known as Brownian motion. Thus, evolution is more than just dynamics. As has been explained in detail elsewhere (Witt 1987, Chap. 1), the crucial qualification that makes dynamics an evolutionary dynamics is the emergence and dissemination of novelty in the evolutionary process. To put it differently, evolution is always a process that has the capacity of expanding its state space through the generation of not previously existing states. Hence, the generation of novelty is generic to all cases of evolution.

On this basis, evolution can be defined in an abstract way as the selftransformation over time of a system under consideration. In this definition, the term "transformation" means a process of change governed by regularities. ${ }^{7}$ The prefix in "self-transformation" points to the endogenous sources and causes of novelty. For epistemological reasons it is useful to split self-transformation into two logically, and usually also ontologically, distinct processes: the emergence and the dissemination of novelty. With the emergence and dissemination of novelty, it is submitted here, the generic, domain-unspecific features of evolution have been identified. The two features materialize in quite different forms in the different disciplines. In biology, we have random mutation and genetic recombination on the one hand and selective replication in the gene pool of a population on the other. In linguistics, to take that example, the invention of new idioms marks the emergence part and their popularization the dissemination part. In the economic domain, given that discipline's focus on human action, novelty is usually seen as emerging from a newly discovered possibility for action which, once taken, is called an innovation. However, any attempt to innovate is likely to trigger learning and be accompanied by it. When the news of the innovation spreads the innovation can disseminate by imitative learning.

\section{Some Methodological Implications}

The generic features of emergence and dissemination of novelty help to understand the epistemological problems which all evolutionary theories face -- independent of their disciplinary domains. By novelty's very nature, its meaning, and hence its future consequences, cannot be completely anticipated. In a deliberate search for a particular novelty, e.g. a solution to a specific problem, it may appear possible to define ex ante necessary conditions which any solution must satisfy. But those necessary conditions rest on the current understanding of the problem. In many cases, the novelty or invention actually discovered re-frames the understanding of the problem. Ex post, the corresponding problem-shift then renders the ex ante postulated necessary conditions

\footnotetext{
${ }^{7}$ Note that the choice of the term "system" is not meant to necessarily imply a system-theoretic interpretation of evolution as suggested by Luhmann and others (cf. Hutter 1994). Rather, it is just a dummy for the different disciplinary objects that evolve: nature in the case of biology, language in the case of linguistics, society in the case of sociology, or the economy in the case of economics. From a physical point of view, as living systems, all evolving entities depend on free energy being accessible to them to maintain their life functions. Availability of free energy is therefore also a necessary, but not sufficient, condition for their further evolution.
} 
obsolete or irrelevant. Moreover, even if this is not the case, ex ante formulated necessary conditions cannot cover all properties of the novel solution -- otherwise it would no longer be novelty. Some features, perhaps important ones, cannot positively be anticipated. (The many, often only much later discovered, negative side effects of technological innovations are a case in point.) This trivial fact is responsible for the constrained predictive power of all evolutionary theories. Because of novelty's very nature, the outcome of evolution cannot be positively anticipated. Yet, since it is possible to derive hypotheses that exclude the occurrence of certain kinds of novelty some testable propositions do always seem feasible ${ }^{8--}$ though they usually imply rather weak predictions.

If the epistemological constraint is taken seriously, what are the implications? As discussed elsewhere (Witt 1987, Chap. 1; 1993), evolutionary theory faces two different kinds of explanatory problem with strongly differing epistemological connotations. The first is to provide explanations for phenomena and conditions without knowing the meaning of the next emerging novelty ("pre-revelation analysis"). The second kind of problem is to explain what happens once novelty has revealed its meaning ("post-revelation analysis"). Roughly speaking, this distinction corresponds to the two tasks of any theory of evolution. The first task is to explain how, and under what conditions, novelty is being generated within the domain of a theory. The second task is to explain what happens as a consequence of novelty having emerged within the domain. The "epistemological boundary" between the problem of emergence and the problem of dissemination not only establishes the constraints on the predictive power of evolutionary theories, but it also implies differing methodological options for the different explanatory tasks.

The bulk of explanatory efforts usually focuses on the second task. ${ }^{9}$ These explanations are indeed much less complicated. This is particularly so under two widely used idealizing assumptions. One assumption is that all relevant properties of a newly generated novelty are already known to the scientific observer. The other assumption is that no further novelty will intervene in the post-revelation analysis. Under these two assumptions, novelty is factually removed from the period of analysis, and its occurrence and revelation is shifted to the antecedent conditions. Under these conditions, the effects triggered by an exogenously given novelty can often be described mathematically by means of ordinary difference or differential equations and their derivatives and solutions. Since there are hardly any mathematical concepts for the emergence of novelty and virtually no algorithmic basis for solving the meaning attri-

8 Take, to use the example given by Hayek (1967b), the neo-Darwinian theory of evolution. Because of the complexity of the genetic recombinatory process there is no way for it to positively anticipate all properties of future generations. But the theory definitely excludes certain novelties from occurring. Even if a forepaw of parent dogs were to be amputated over several generations, the theory predicts that no puppy will ever be born that has no forepaw. However arbitrary this hypothesis may appear on first sight, it offers the possibility for a test that discriminates between Darwin's theory and the rivaling Lamarckian hypothesis of the heredity of acquired traits.

9 This is even true in evolutionary biology, where the lion's share of theorizing deals with what may be classified as "selection" and "retention" processes according to the scheme of Campbell (1965). The production of genetic novelty by mutation and recombination ("variation") is a comparatively special topic. 
bution problem (cf. the discussion in Egidi 1992), this condition defines the presently binding boundary for mathematical modeling in evolutionary economics.

For analyzing the effects and characteristic phenomena of dissemination processes, formal modeling is useful. In fact, many implications can otherwise hardly be derived $^{10}$. As discussed in Witt (1992), these phenomena include frequency-dependency effects and occupancy effects. Furthermore, there are effects of critical mass thresholds and lock-in effects. These effects often occur as "emerging properties", which is to say that they only turn up if, in the evolutionary process, certain ranges of parameter values are exceeded. These dynamic phenomena help in understanding the peculiar coexistence of two apparently conflicting ideas in evolutionary theories. On the one hand there is a belief in general procedural regularities. On the other hand, there can be no doubt about the historical specificity of the evolutionary process. Can regularity and historicity go together? A tentative answer could be: even if history is made up of a sequence of unique episodes, in these episodes, and in the transition between them, something can repeat itself, i.e. regularities can occur. Regularities may reside in learning and imitation phenomena, in diffusion and selection phenomena, and even in the very generation of novelty. Among the recurrent features one can expect, for example, frequency-dependency and occupancy effects, critical mass and lock-in effects. This is to say on the one hand that nomological knowledge by means of which at least some aspects of historical particularities can be explained is feasible. On the other hand, the evolutionary process in its entirety is "irrevocable" (Georgescu-Roegen 1971, pp.196197). It cannot repeat itself identically even though, as a consequence of its regularity, it may display some recurrent patterns.

\section{Ontological Claims: the Continuity Hypothesis}

In the previous section some generic features which are supposed to characterize evolution -- the emergence and dissemination of novelty -- have been discussed. This means that all domain-specific evolutionary processes are expected to share these features and some abstract principles that may follow. At the ontological level, this implies that all evolutionary processes have something in common without necessarily being connected to one another. Indeed, whether or not there are also (inter-) dependencies between the various domain-specific processes of evolution, or whether some of them even refer to the same phenomena in reality, is a different ontological question. It is the subject of this section. In order to discuss it, two further views of how Darwinian evolutionary biology and, for that matter, evolutionary economics, relate at the ontological level will be surveyed.

10 Examples in evolutionary economics are individual learning, imitation, and the resulting collective dynamics. As Brenner (1999) shows, they can be represented by diffusion processes on the basis of some version of the master equation. In some cases, the replicator dynamics equation (now popular in evolutionary game theory, cf. Hofbauer and Sigmund 1988, Chap. 4) which gives an abstract account also of selection processes can be used. 
The first, and most radical, view assumes that the neo-Darwinian theory of natural selection can be extended to also explain economic behavior of modern man. ${ }^{11}$ Thus, the ontological basis of evolutionary economics, evolutionary biology in general, and sociobiology in particular is assumed to be essentially the same. By implication, the emergence and dissemination of novelty would have to be understood as referring to the genetic level only. The justification for this assumption may be sketched as follows. Economic phenomena result from human behavior. Humans are themselves a product of natural selection. Accordingly, the Darwinian theory of evolution may be considered directly relevant to the explanation of human economic behavior. Observable economic behavior should therefore be explicable in terms of its contribution to genetic fitness.

The problem with such an explanation is, of course, that it would be valid only if selection pressure on humans is still tight enough for deviations from the best fit behavior (in terms of reproductive success) to be wiped out. While this may be a reasonable working hypothesis for early, primitive economies, the conditions in the much more productive modern economies seem to be different. Indeed, in the latter, the most significant part of the adaptations in economic behavior usually occur within one generation, i.e. at a pace much more rapid than that of inter-generational, genetic adaptation. These adaptations reflect the emergence and dissemination of novelty at the cultural level: ideas, practices, habits, artefacts etc. They result from the evolutionary dynamics of learning and insight which are inaccessible to the neo-Darwinian theory of natural selection.

The second view, advocated by the present author (cf. Witt 1987, Chap. 3; 1991; 1996; 1999), is epitomized by what may be called the "continuity hypothesis". In this view, the fact that humans and their "hardwired" endowment are a result of natural selection also figures prominently. However, these genetic endowments are considered as only setting the stage for yet other forms of evolution which have emerged under the influence of the unfolding human culture. They follow their own regularities and interact both among themselves and with natural evolution in an increasingly icher and more complex way. This means that an ontological continuity over time is assumed in which new forms of change have been generated within the freedom left by the constraints of Darwinian theory -- and, hence, without invalidating that theory.

Under natural selection, innate dispositions and adaptation mechanisms and programs in humans have been shaped which define the basic behavioral repertoire upon which other forms of evolution rest. In the early phases of human culture it is likely that the two forms of evolution have interacted. However, the synergisms between the natural and cultural results of natural selection eventually allowed forms of human behavior to emerge which had a strong relative reproductive success compared to other species (Corning 1983). As a consequence, selection pressure was significantly reduced

11 Cf., e.g., Hermann-Pillath (1991), Rubin (1982), Robson (2001); for a critical view cf. Witt (1985) and Hallpike (1996). A modified version of this strategy has informed anthropological research under the label of the coevolution hypothesis. It is argued that cultural behavior in primitive societies can be explained by the joint fitness value of genetic and cultural traits, cf. Durham (1976), Boyd and Richerson (1994). 
and man's genetic endowment has remained much the same since then. The more selection pressure faded, the less systematically selected was behavior which contributed to genetic fitness. Behavioral variety could increase and include variants which had little or no adaptive value. This gave room for human culture, institutions, and advances in economy and technology to evolve according to their own regularities. These regularities are compatible with, and build on, the fact that the innate individual dispositions and adaptation mechanisms are still in place.

Thus, the continuity hypothesis postulates a historical transition. "The origin of the species by means of natural selection", as Darwin (1859) put it, is that form of evolution occuring in reality which antedates, in historical time, other forms of evolution considered here. It is exclusively characterized by the emergence and dissemination of novelty at the genetic level. But this has shaped the ground, and still defines the constraints, for man-made, or cultural, evolution. A plurality of partly interactive evolutionary processes could thus develop in which novelty of very different quality emerges and disseminates at diverse levels. Darwinian theory is directly relevant for understanding both the origin of economic evolution in human phylogeny and continuing influence of innate elements on human economic behavior. Yet, in the further course of economic evolution, human behavior and, correspondingly, economic activities and their collective outcomes underwent a metamorphosis into the distinct, idiosyncratic forms observable in present-day economies. To explain the emergence of the latter, Darwinian theory is not sufficient. What is needed in addition are theories which explain the several facets of cultural evolution.

The continuity hypothesis just specified has important implications for a broadly conceived research program in evolutionary economics. To give an example: the hypothesis suggests ways substance can be added to the theory of human preferences which, by and large, has been treated until now as a "black box" in economics. To escape from the unnecessarily agnostic preference subjectivism in modern economic theory and to reconstruct and explain some objective features of revealed human preferences, recourse can be taken to the remnants of the different, simultaneously operating forms of evolution: the genetic dispositions, the behaviorally reinforced attitudes, and the cognitively acquired knowledge and beliefs. The resulting theory (cf. Witt 2001) explains how human preferences emerge from some innate dispositions and non-cognitive learning mechanisms, and how their revelation is affected by socially shared cognitive frames and subjective experience.

To give another example: the proposed continuity hypothesis allows us to better come to grips with the evolutionary change in the constraints on human productive and consumptive activities. At present, economic theory reflects on these constraints only in an extremely abstract form, namely, to the extent to which they affect the transformation of unspecified inputs into unspecified outputs in anthropogenic production. The continuity hypothesis offers a more concrete approach (cf. Witt 2003). Since evolution in nature has defined the constraints for what can evolve elsewhere, the changing production forms in human phylogeny can easily be reconstructed against that background. The crucial effect of cultural evolution that comes to the fore here is not so much the economizing on scarce resources (which is usually emphasi- 
zed in economics), but rather the cumulative problem solving and knowledge generation on the one side, and a successive creation of new problems on the other. On balance, the human economy's growing capacity to generate, apply, and improve cultural knowledge has up to now increasingly allowed the natural constraints on human economic activity to be slackened.

A significant feature worth mentioning is the massively enhanced access to free energy, particularly fossil energy resources. The increasing release of large parts of the human society from being limited to the age-old uses of human time for physical work has enabled humankind to generate and apply ever more knowledge -- a kind of autocatalytic cycle (cf. Buenstorf 2000). It has allowed the niche for the human species to be enlarged, at least temporarily. Moreover, the command over natural resources has increased dramatically for almost all its members currently alive. (In economic growth theory these consequences are usually reflected by growing per capita income worldwide and unprecedented increases in labor productivity.) On the other hand, the evolutionary process that has produced these amenities has also triggered developments with an uncertain, and possibly highly problematic, longer term impact on nature, the ultimate foundation of the human economy. Unfortunately, the epistemological boundary discussed in the previous section prevents us from making predictions of the meaning of future new knowledge. How the balance between problem solving and problem generating will develop in the future is therefore unknown. It is a matter, alternatively, of optimistic hopes or pessimistic fears.

\section{Conclusions}

An attempt has been made here to clarify the generic features of evolution and some of the implications that follow from these features. The attempt was motivated by the fact that evolution is believed to occur in many disciplines. As a tribute to the intellectual attraction of the neo-Darwinian theory of evolution, the evolutionary processes in other domains are often also conceptualized in terms of Darwinian concepts. Some modern Darwinists even propagate the concepts of variation, selection, and replication as universally applicable. However, as has been argued, when it comes to making sense of evolution in non-biological domains, recourse to Darwinian concepts is neither a necessary heuristic strategy nor is it always a helpful one. There are good reasons to search for generic features of evolution in a way that transcends all domain-specific characteristics. These reasons have been discussed and a way of identifying generic features has been pointed out. Two concrete generic features have been suggested and some of their implications, which are relevant for analyzing evolution in all domainspecific manifestations, have been outlined.

Finally, an attempt has been made to confront the findings with an issue that seems of some importance for the post-Darwinian natural philosophy. How does the idea that various forms of evolution have emerged in different domains fit the Darwinian world view? And, accordingly, how can the various domain-specific evolutionary theories such as, for instance, evolutionary economics, be accommodated by the world view of the moderns sciences which is strongly influenced by the neoDarwinian theory of evolution? The answer that has been suggested is a specific onto- 
logical claim which has been dubbed the "continuity hypothesis". The hypothesis does attribute relevance to the neo-Darwinian theory of evolution for explaining evolutionary phenomena in non-biological disciplinary domains such as the economic domain. Hence it subscribes to a Darwinian world view. However, unlike in some contributions inspired by sociobiology, the relevance does not lie in its direct applicability to explaining the evolution of economic behavior. Nor is the relevance that of a master theory which provides abstract tools, as Universal Darwinism has it. Instead, the relevance of neo-Darwinian theory rather is the following. It is the theory that explains how the basis has been generated and constraints are still shaped for those forms of evolution which have emerged later under the influence of the unfolding human culture. The human economy and its tremendous historical change is a congenial example.

\section{BIBLIOGR APHY}

Alchian, A.A. (1950). "Uncertainty, Evolution, and Economic Theory", Journal of Political Economy 58, 211 221.

Bergstrom, T.C. (2002). "Evolution of Social Behavior: Individual and Group Selection", Journal of Economic Perspectives 16, 67-88.

Binmore, K. (1994). Playing Fair - Game Theory and the Social Contract I. Cambridge, MA: MIT Press.

- (1998). Just Playing - Game Theory and the Social Contract II. Cambridge, MA: MIT Press.

Boyd, R, and Richerson, P.J. (1994). "The Evolution of Norms: An Anthropological View", Journal of Institutional and Theoretical Economics 150, 72-87.

Brenner, T. (1999). Modelling Learning in Economics. Cheltenham: Edward Elgar.

Buenstorf, G. (2000). "Self-organization and Sustainability: Energetics of Evolution and Implications for Ecological Economics", Ecological Economics 33, 119-134.

Campbell, D.T. (1965). "Variation and Selective Retention in Socio-cultural Evolution", in Barringer, H.R., Blankstein, G.I., Mack, R.W. (eds.). Social Change in Developing Areas: A Re-interpretation of Evolutionary Theory. Cambridge, MA: Schenkman, 19-49.

Corning, P.A. (1983). The Synergism Hypothesis: A Theory of Progressive Evolution. New York: McGraw-Hill.

Darwin, C. (1859). On the Origin of the Species by Means of Natural Selection or the Preservation of Favored Races in the Struggle of Life. London: John Murray.

Dawkins, R. (1983). "Universal Darwinism", in Bendall, D.S. (ed.). Evolution from Molecules to Man. Cambridge: Cambridge University Press, 403-425.

- (1986). The Blind Watchmaker. Harlow: Longman.

Durham, W.H. (1976). "The Adaptive Significance of Cultural Behavior", Human Ecology 4, 89-121.

Egidi, M. (1992). "Organizational Learning, Problem Solving and the Division of Labor", in Egidi, M., Marris, R. (eds.). Economics, Bounded Rationality and the Cognitive Revolution. Aldershot: Edward Elgar, 148-173.

Georgescu-Roegen, N. (1971). The Entropy Law and the Economic Process. Cambridge, MA: Harvard University Press.

Hallpike, C.R. (1996). "Social Evolution", Journal of Institutional and Theoretical Economics 152, 682-689.

Hawkins, M. (1997). Social Darwinism in European and American Thought, 1860-1945. Cambridge: Cambridge University Press.

Hayek, F.A. (1967a). "Dr. Bernhard Mandeville", Proceedings of the British Academy 12, London: Oxford University Press.

— (1967b). "The Theory of Complex Phenomena", in Hayek, F.A. Studies in Philosophy, Politics and Economics. Routledge \& Kegan Paul, 22-42.

Hermann-Pillath, C. (1991). "A Darwinian Framework for the Economic Analysis of Institutional Change in History", Journal of Social and Biological Structures 14, 127-148.

Hodgson, G.M. (1999). Evolution and Institutions. Cheltenham: Edward Elgar. 
- (2001). How Economics Forgot History: The Problem of Historical Specificity in Social Science. London: Routledge

Hofbauer, J., Sigmund, K. (1988). The Theory of Evolution and Dynamical Systems. Cambridge: Cambridge University Press.

Hutter, M. (1994). "The Unit that Evolves: Linking Self-Reproduction and Self-Interest", in Magnussen, L. (ed.). Evolutionary and Neo-Schumpeterian Approaches to Economics. Dordrecht: Kluwer, 49-64.

Knudsen, T. (2001). "Nesting Lamarckism within Darwinian Explanations: Necessity in Economics and Possibility in Biology?", in Laurent, J., Nightingale, J. (eds.). Darwinism and Evolutionary Economics. Cheltenham: Edward Elgar, 121-159.

Maynard Smith, J. (1982). Evolution and the Theory of Games. Cambridge: Cambridge University Press.

Mayr, E. (1991). One Long Argument. Cambridge, MA: Harvard University Press.

Metcalfe, J.S. (2002). "On the Optimality of the Competitive Process: Kimura's Theorem and Market Dynamics", Journal of Bioeconomics, forthcoming.

Morley, J. (1874). On Compromise. London: Chapman and Hall.

Nelson, R.R. (1995). "Recent Evolutionary Theorizing About Economic Change", Journal of Economic Literature $33,48-90$.

Nelson, R.R, Winter, S.G. (1982). An Evolutionary Theory of Economic Change. Cambridge, MA: Harvard University Press.

- (2002). "Evolutionary Theorizing in Economics", Journal of Economic Perspectives 2, 23-46.

Penrose, E.T. (1952). "Biological Analogies in the Theory of the Firm", American Economic Review 42, 804819.

Popper, K. (1960). The Poverty of Historicism. London: Routledge \& Kegan Paul, 2nd edit.

Richards, R.J. (1992). The Meaning of Evolution: the Morphological Construction and the Ideological Reconstruction of Darwin's Theory. Chicago: Chicago University Press.

Robson, A.J. (2001). "The Biological Basis of Economic Behavior", Journal of Economic Literature 39, 11-33.

_ (2002). "Evolution and Human Nature", Journal of Economic Perspectives 2, 89-106.

Rubin, P.H. (1982). "Evolved Ethics and Efficient Ethics", Journal of Economic Behavior and Organization 3 , 161-174.

Ruse, M. (1979). The Darwinian Revolution. Chicago: University of Chicago Press.

Rutherford, M. (1998). "Veblen's Evolutionary Programme: A Promise Unfulfilled", Cambridge Journal of Economics 22, 463-477.

Samuelson, L. (2002). "Evolution and Game Theory", Journal of Economic Perspectives 2, 47-66.

Schumpeter, J.A. (1912/34). Theorie der wirtschaftlichen Entwicklung. Leipzig: Duncker \& Humblot, 1912; first English edition Theory of Economic Development. Cambridge, MA: Harvard University Press, 1934.

Veblen, T. (1898). "Why Is Economics Not an Evolutionary Science?" Quarterly Journal of Economics 12 , 373-397.

_ (1899). The Theory of the Leisure Class - An Economic Study of Institutions. New York: MacMillan. (1914). The Instinct of Workmanship, and the State of the Industrial Arts. New York: MacMillan.

Winter, S.G. (1964). "Economic 'Natural Selection' and the Theory of the Firm”, Yale Economic Essays 4, $225-272$.

Witt, U. (1985). "Economic Behavior and Biological Evolution: Some Remarks on the Sociobiology Debate", Journal of Theoretical and Institutional Economics (formerly Zeitschrift fuer die gesamte Staatswissenschaft), 141, 365-389. - (1987). Individualistische Grundlagen der evolutorischen Oekonomik. Tuebingen: Mohr-Siebeck. (1991). "Economics, Sociobiology, and Behavioral Psychology on Preferences", Journal of Economic Psychology 12, 557-573.

_ (1992). "Evolutionary Concepts in Economics", Eastern Economic Journal 18, 405-419.

- (1993). "Emergence and dissemination of Innovations: Some Principles of Evolutionary Economics", in: Day, R.H., Chen, P. (eds.). Nonlinear Dynamics and Evolutionary Economics. Oxford: Oxford University Press, 91-100.

_ (1996). "A Darwinian Revolution in Economics?", Journal of Institutional and Theoretical Economics 152 , $707-715$.

- (1999). "Evolutionary Economics and Evolutionary Biology" in: Koslowski, P. (ed.). Sociobiology and Bioeconomics. Berlin: Springer, 279-298. 
_ (2001). "Learning to Consume - A Theory of Wants and the Growth of Demand", Journal of Evolutionary Economics 11, 23-36.

— (2002). "How Evolutionary is Schumpeter's Theory of Economic Development?", Industry and Innovation 9, 7-22.

- (2003). "Production in Nature and Production in the Economy - Second Thoughts about Some Basic Economic Concepts".

Young, P. (1998). Individual Strategy and Social Structure: An Evolutionary Theory of Social Institutions. Princeton: Princeton University Press.

Ulrich WITt is the director of the Evolutionary Economics Unit of the Max Planck Institute for Research into Economic Systems and professor of economics at the Friedrich Schiller University, both in Jena, Germany. He did his Ph.D. in economics at the University of Goettingen in 1979 and finished his habilitation at the University of Mannheim in 1985. From 1988-1995 he held a chair in economic theory at the University of Freiburg in Germany before he assumed his current position.

Address: Evolutionary Economics Group, Max-Planck-Institute for Research Into Economic Systems. Kahlaische Str. 10, D-07745 Jena, Germany. E-mail: witt@mpiew-jena.mpg.de 